in the lay press can be a source of misinformation which might lead women to change methods of contraception or to select a different initial method. However, the reading and interpretation of this same medical literature by physicians and its effect on their discussion of various methods with patients has perhaps a more profound impact on choice.

Women come to the consultation with many questions and ask their doctor to interpret what often appears to be conflicting information on contraceptive methods. By not elaborating on the changing attitudes of the doctors who were doing the family planning in the Palatine family planning clinic, the authors sought to explain the decrease in the choice of the pill over the four-year period by the influence of the media on the public rather than by the influence of the changing in attitude of the doctors as these changes affected the consultation. The power of the doctor in the doctor-patient relationship to influence choice is well known and should not be ignored when attempting to analyse changes in patients' behaviour.

The differences in contraceptive choice between the authors' data and the American study they cite may reflect prevailing biases and attitudes of the doctors more than the patients. Controlled studies taking into consideration physicians' attitudes toward various contraceptive methods as well as other issues, such as physicians' feelings about abortion as an alternative to contraceptive failure, should be carried out if a true picture of the reasons for the changing pattern of contraceptive choice is desired.

Glyncorrwg Health Centre,

Port Talbot, West Glamorgan

JOHN J FREY

\section{Sternal puncture}

SIR,-In his paper, Dr Clifford Hawkins (15 September, p 638) points out the anxiety and physical discomfort caused by, among other investigations, sternal puncture, and mentions that fear of needles is very common among patients and that even the sight of someone approaching with a syringe causes alarm.

I am sure that his patients would find that the posterior iliac crest is a better site for marrow biopsy. Though biopsy is technically slightly more difficult at this site, it is much less painful, potentially less dangerous, and yields a better specimen-and the patient can see little of what is being done.

\section{E R Craven}

Kettering and District General

Hospital,
Kettering, Northants NN16 8UZ

\section{Babesiosis in man}

SIR, - We read with interest the case report bv Dr J H Entrican and others on babesiosis in man (25 August, $p$ 474). They are, however, incorrect to state that this is the first recorded case of this infection in the United Kingdom. A patient infected by Babesia divergens was reported from Northern Ireland in $1968,{ }^{1}$ and described more fully the following year. ${ }^{2}$

Our patient had also had a splenectomy and presented with massive intravascular haemolysis and renal failure. There was strong evidence that he acquired his infection while on a caravan holiday, cases of redwater fever in cattle being reported from that area during the same month. At that time there had been only two previously recorded cases of this infection in man.

Bridport, Dorset DT6 5NA

C Cotton KenNedy

Mary G McGrown

J H ROBERTSON

Renal Unit,

Belfast City Hospital,

Belfast BT9 $7 \mathrm{AB}$

' Fitzpatrick, J E P, et al, Nature, 1968, 217, 861. Fitzpatrick, J E P, et al, British Medical fournal, 1969, 4, 770 .

\section{Unwanted journals}

SIR,-As a principal newly arrived in general practice from vocational training I receive the following free: Update, General Practitioner, Medicopost, Medicine, Pulse, Hospital Doctor, On Call, Medical News, World Medicine, and Prescribers' fournal. Several of these carry a common computer number and have jointly located my new home. Since like most mortals I live 24-hour days in which there are certain other functions to fulfil, I choose to read only three of these, plus chosen subscription journals. The rest I jettison unread.

The costs of scarce raw paper, printing, packaging, and distribution must be borne by the advertisement revenue, presumably out of profits on pharmaceuticals. However, the less definable costs of further burdening the Post Office and of waste disposal are borne by all of us. We doctors also have the nuisance of sorting wheat from chaff. Worse, the Great Unwanted ignore my repeated requests for cancellation. How can we curtail this flood of unrequested mail, brought on us by our prescribing power? Does anyone agree that this is urgent, or is this another One Lone Voice Protesting Subject (OLVPS), like that of the admirable Dr D H Judson (8 September, p 613)?

North Berwick,
East Lothian EH39 4RE

ROGER SIMMONS

\section{Post-marketing surveillance of drugs}

SIR,--Your readers might infer from Professor D H Lawson's letter (1 September, p 546) in response to our paper on the methodology of monitored release (21 July, p 163) that the terms "monitored release" and "post-marketing surveillance" are synonymous. We would like to point out that the methodology described by us was quite different from that suggested by Professor Lawson. ${ }^{12}$

Professor Lawson criticises us for concluding "that post-marketing surveillance studies are unlikely to add much to the knowledge and understanding of new drugs already gained from preregistration clinical trials." But in fact the conclusion in the paper related specifically to monitored release of buprenorphine and not to post-marketing surveillance in general.

We defend our statement that "monitored release, however large the cohort size, without a suitable (randomised ?) control group, is a methodological impasse when rare events are considered." Professor Lawson's observations on this statement refer to common serious events with an incidence of one in 500, and not to rare events. If an effect has not been seen in 1921 patients the true incidence is less than one in $500(95 \%$ confidence limit) and monitoring of much larger numbers should be necessary. The problem of detecting rare effects and of proving causation, however, remains.

To add to the confusion, Professor Lawson emphasises that our study did not give much useful information about reasonably common delayed adverse drug effects or effects arising after long-term use of the compound. This does not seem to us to be relevant to a product used intermittently by injection for short periods in the management of moderate-tosevere pain.

A W HaRcus

A E WARD D W SMITH

Pharmaceutical Division,

Reckitt and Colman,

Kingston-upon-Hull HU8 7DS

${ }^{1}$ Lawson, D H, and Henry, D A, British Medical fournal, 1977, 1,691. 1979, 7, 13. British fournal of Clinical Pharmacology,
awson,

\section{Vitamin $B_{12}$ : an area of darkness}

SIR,-In their interesting review on vitamin $\mathrm{B}_{12}$ (1 September, p 533) Professor D M Matthews and Dr J C Linnell state that the early view that cyanocobalamin was the predominant form of vitamin $B_{12}$ present in the body was not doubted until the early 1960 s, when the existence of adenosylcobalamin and methyclobalamin was first demonstrated. May I suggest that their "area or darkness" was perhaps not quite so dark for quite so long?

Already in the early 1950 s, only a few years after the isolation of pure cyanocobalamin, biochemists and nutritionists were becoming increasingly aware of the predominant role played by hydroxocobalamin; and in 1955 the late Dr F Wokes and I proposed a hypothetical sulphur-transfer cycle involving hydroxocobalamin in the synthesis of sulphur-containing amino-acids. ${ }^{1}$ That hypothesis was based on the clearly stated assumption that hydroxocobalamin rather than cyanocobalamin was the active form of the vitamin present in the body.

Berne, Switzerland

C W PICARD

1 Wokes, F, and Picard, C W, American fournal of Clinical Nutrition, 1955, 3, 383.

\section{Cancer of the ovary}

SIR,-I was truly fascinated by the leading article on ovarian cancer (22 September, $p$ 687). As I read the introductory paragraphs on the world-wide differences in racial incidence and the equally interesting demographic and epidemiological data I thought I must write a short note of congratulation-why don't I do this more often, I thought. Reading on, I found a detailed discussion of the everexpanding field of chemotherapy, the hopes for VP16, and the almost inevitable suggestion that "Greater accuracy in the choice of chemotherapy for individual patients may, in the future, be obtained by drug selection challenges on the xenografted tumours in immune deficient mice or cell colonies obtained from laparotomy specimens." I winced a little as I recalled the extravagant enthusiasm for this approach by oncologists in, for example, Germany at least 20 years ago. 